\title{
Pragmatics of humour in memes in Spanish
}

Francisco Yus

University of Alicante

Spanish in Context 18(1), 2021

In this paper the discourse of a specific type of meme in Spanish, the image macro, is analysed, together with several ways in which memes generate humorous effects. Two main areas are addressed: (a) how humour arises from the processing of the text in the meme (decoding of the text plus further inferential enrichment); and (b) how humour relies on specific combinations of the text and the image in the meme. The pragmatic framework used in the analysis will be relevance theory (Sperber and Wilson 1995), which in previous research (especially Yus 2016) has proven to be a valid foundation for the analysis of humour.

Keywords: memes, internet humour, relevance theory 


\section{Introduction}

This paper deals with memes in Spanish. As will be defined in more detail below, memes are varied multimodal discourses that typically spread on the Net with an underlying humorous intention (but they may also be rather critical or satirical). An inherent quality of memes is that they spread either unmodified or with greater or lesser alterations in shape and content. As such, many memes exhibit a cross-cultural validity, since they deal with universal topics or the characters depicted are well-known to a great variety of users. However, some Spanish memes do possess an intra-cultural quality, in the sense that either they are only found in Spanish virtual interactions or the topics addressed are local and therefore they only make sense to Spanish addressee users.

The paper starts with a description and definition of Internet memes. The next Section deals with memes and humour, describing the main humorous qualities of memes. The next Section deals specifically with humour and memes in Spanish and focusing on humour arising from the processing of the text of the meme or from text-image combinations in the meme. The paper ends with some concluding remarks.

\section{Internet memes}

Internet memes are groups of digital items (such as images or videos) that share common characteristics, are created with awareness of the existence of other memes (i.e., in a series of inter-related memes) and are distributed online by multiple participants (Shifman 2014). The term "applies to any artifact (a film, spoof, rumor, picture, song, etc.) that appears on the Internet and produces countless derivatives by being imitated, remixed, and rapidly diffused by countless participants in technologically mediated communication" (Dynel 2016, 662). The format of memes varies, including viral images, videos, text-image combinations and catchphrases under constant modification by users, and with a propensity to travel as fast as the Internet can move them (Coleman 2012, 109).

Memes exhibit unifying attributes despite their apparent heterogeneity. First and foremost, their capacity to get replicated (or be slightly altered) and spread across a population of users. More specifically, Shifman $(2014,18)$ proposes three shared qualities: (1) gradual propagation from individuals to society, (2) reproduction via copying and imitation, and (3) diffusion through competition and selection. Similarly, Hadley (2016, 678) proposes the qualities of intertextuality, recognisability and repeatability (see also Greidina 2017, 297-299).

One final quality of memes worth mentioning is the fact that, normally, individual memes are regarded as part of a series of memes with which they share some characteristics; users need to identify this quality in order to obtain the full intended (humorous) effects (Segev et al. 2015, 418; Nissenbaum and Shifman 2017, 484). Besides, users need to be able to retrieve some expected background knowledge that is essential to interpret the content of the meme appropriately. In general, part of the enjoyment of memes relies on the user's awareness of being capable of retrieving the contextual information (background knowledge included) that allows for optimal processing of the meme. As Denisova $(2016,72)$ correctly observes, those who are unfamiliar with the rules 
of digital discussion and styles of Internet slang, or possess limited awareness of the broader socio-political context, may consider memes meaningless. In order to be able to read a meme, the user needs some digital literacy or basic familiarity with this format of communication. Further, mutual awareness of group accessibility to the necessary context and background assumptions fosters communal ties among users (Yus 2018). As Csordás et al. $(2017,252)$ point out, memes construct and fuel affinity-spaces of shared knowledge and meanings. Certainly, the majority of successful Internet memes are more likely to spread through homogenous communities (in the form, for example, of insider jokes or intertextuality) and social networks rather than through the Internet at large.

Several authors have proposed different types of memes. Milner (2012) proposes two major categories: remixed image and stable image. The former refers to transforming an already established image. The latter refers to the images that spread without transformation. The remixed image category includes two subsets: single images and stacked images. Single images are those remixed instances which appear in a single panel. Stacked images combine a group of new mixed images.

This paper will focus on the image-macro meme, made up of a line of text on top of the meme, another text at the bottom and one image in the middle, with a number of interesting text-image combinations with pragmatic implications (see Yus 2019). According to Tay $(2015,49)$, image macros are generally simpler to produce, since there are computer applications that facilitate the creation and alteration of memes. The term "image macro" is a widely accepted expression used to describe an image with a superimposed caption, usually for humorous effect. From this perspective, a macro can be seen as the automated processes that users go through to add captions to images in the accepted style.

\section{Memes and humour}

Memes are meant to draw the user's attention and create the expectation of a relevant interpretive outcome. For a mental-effort-relieving meme processing, the fact that the image macros have developed into a clearly identifiable genre is crucial (Carter 2016, 26, Willmore and Hocking 2017, 151). Initial decoding of the meme genre favours a specific line of processing and parallel expectations of relevance, the user often assuming that humour is intended and therefore the meme will not be relevant in a purely informational sense. This idea of "relevance" comes from relevance theory, a cognitive pragmatics theory (Sperber and Wilson, 1995). It stresses that there is a gap between what is literally said (or written), that is, what is coded, and what is intended and eventually interpreted, which is inferred. The cognitively rooted human tendency to search for relevance guides the addressee in filling up this informational gap. In this sense, finding a relevant interpretation involves identifying (a) what the speaker intended to say explicitly, and/or (b) what the speaker intended to imply, together with (c) access to the speaker's intended context (i.e. the information from context that the sender intended the addressee to recover as part of the overall interpretation of the discourse).

Besides, the correct identification of the meme genre is an indicator of in-group membership (Meikle 2016, 55). As Ballesteros Doncel (2016, 26) correctly stresses, the grammar of memes cannot be dissociated from the digital capabilities of those who create and re-create them. This initial identification may impact the user and make him/her aware 
of being part of a certain group of those who manage and are fully updated on the kind of specific information that is currently exchanged on the Net. For instance, in the case of the famous LOLCat memes, improper application of the unspoken rules of meme construction and of its special textual features marks the user as an outsider among the LOLCat community (Miltner 2014). Indeed, these memes demand faithful compliance with conventions of font, text placement, image subject, and animal characterization as integral to the enjoyment of the LOLCat meme. This adherence to specific design elements is considered paramount to LOLCats, and also reinforces collective bonding and awareness of group membership.

Indeed, memes are typically meant to be humorous although, as happens with cartoons in the press, memes may also be highly critical, for instance those with a political connotation (Yoon 2016, 97). But in general, when users are sent a meme, one of the default expectations is that they be humorous in some way (Miltner 2014, Yus forthcoming). This is coherent with the fact that users tend to share more positive than negative stories. They like to transfer surprising, interesting and useful content that makes other users feel good while stressing the entertaining and upbeat attributes of the "sender users," and this default interest in information transmission explains the centrality of humour as the most forwarded category in the viral spread of information (Shifman 2014, 66-67). Breheny $(2017,72)$ further underlines the importance of humour in memes by stating that it is essential for memetic success: "The use of humour in image memes serves their function as relatable content by relying on jokes which revolve around an audience's familiarity with pop culture, politics and real world events." Besides, humour signals similarity, fosters closeness, conveys sociability and can therefore foster empathy from an audience.

Many image macro memes such as the ones analysed in this paper are clearly humorous and they even exhibit the typical incongruity-resolution pattern ${ }^{1}$ of humorous discourses (see Yus 1997, 2016, 2017, forthcoming), as proposed by Suls (i.e., 1983) even though variations are found which are inherent to this medium. An example is found in Dynel (2016), who analyses memes such as the ones quoted in (1-2):

(1) Top text: Why don't you slip into something more comfortable.

Image: $\quad$ Famous grumpy cat. $^{2}$

Bottom text: Like a coma.

(2) Top text: Runs into her ex and her new boyfriend.

Image: $\quad$ Image of a fierce-looking dog.

Bottom text: Puts car in reverse and hits them again.

Clearly, these memes exhibit humour-generating inferential stages similar to the ones expected for incongruity-resolution-centred jokes, since the initial accessible interpretation of slip into and runs into has to be invalidated as the subsequent stretch of discourse is processed (an incongruity turns up). The user then has to backtrack and re-interpret these

1. "The perceiver meets with an incongruity (usually in the form of a punch line or a cartoon) and then is motivated to resolve the incongruity either by retrieval of information in the joke or cartoon or from his/her own storehouse of information. According to this account, humour results when the incongruity is resolved; that is, the punch line is seen to make sense at some level with the earlier information in the joke" (Suls 1983, 43).

2. Grumpy cat is a famous cat used in memes because it looks as if it is constantly angry due to its peculiar face. 
verbs differently so as to obtain a resolution. A similar humorous pattern is found in several memes in Spanish. An example is (3) below:

$\begin{array}{ll}\text { (3) Top text: } & \text { Aún no está todo perdido. } \\ & {[\text { All is not lost yet }]} \\ \text { Image: } & \text { Picture of the coach of the Spanish football team. } \\ \text { Bottom text: } & \text { Aún podemos perder contra Australia. } \\ & \text { [We can still lose against Australia]. }\end{array}$

The user who interprets this meme initially infers that for the Spanish football team there is still room for winning (and eventually moving on to the next phase of the championship), but the bottom text invalidates the initial interpretation and the user has to replace it with a new interpretation, this time that the football team is bound to lose even one more match.

This incongruity-resolution pattern is centred upon the processing of the text in the meme. However, as argued in Yus (2013a, 2013b, 2016, 2017), there is also a similar pattern but this time regarding the mental construction of a suitable situation in order to make sense of the joke. This situation was labelled make-sense frame in Yus (2013a, $2013 \mathrm{~b}$ ). This term refers to the extraction of general information about the world and everyday situations that is stored as accessible chunks of encyclopaedic information (specifically stored as "I conceptualize X as $p$ " or as a more factual "I believe that $p$ "). This information is often retrieved unconsciously in order to make sense of the intended scenario for the comprehension of the joke (Yus 2016, 2017). The term overlaps with others typically used for this kind of information retrieval, such as frame, schema or script, which often exhibit a great deal of overlapping in their scopes. Consider the memes in (4$5)$ :

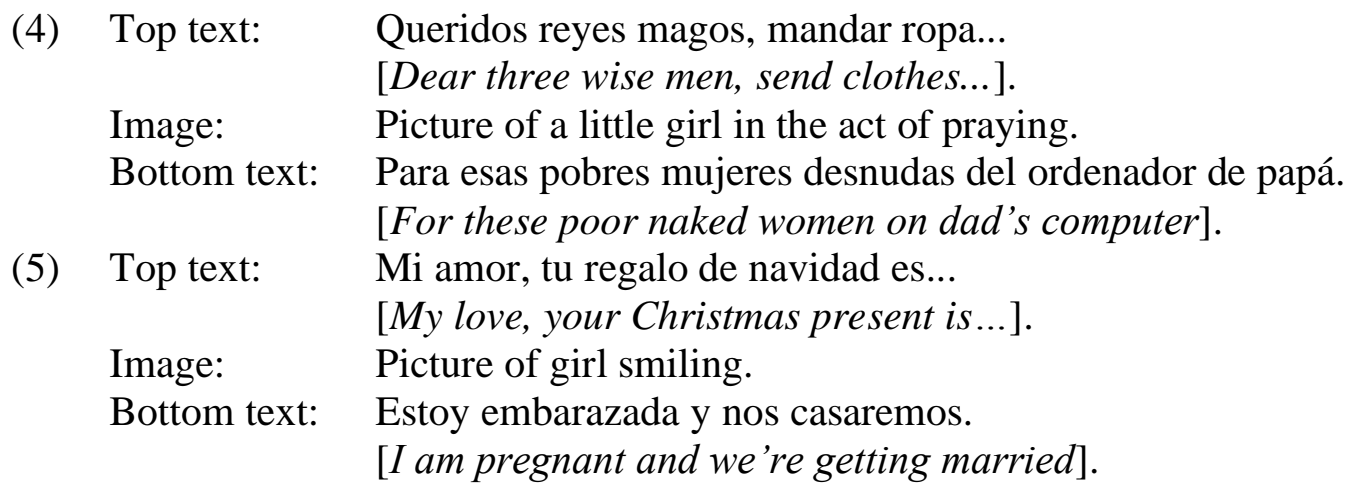

In both (4) and (5), the user activates encyclopaedic knowledge related to Christmas, initially constructed as a make-sense frame within which the text of the meme will be processed, including information about good wishes, giving presents, etc. However, the user suddenly comes across the bottom text of the memes that is incongruous with the information inferred so far, which forces a change or alteration of the Christmas makesense frame (still active in the user's short memory store). In (4), the humour lies in a total change of scenario and in the fact that, for the little girl, the naked girls need clothes, but for the user the reason why they are naked is obviously different. In (5), the smiling girl is announcing a Christmas present. The user anticipates some pleasurable outcome of the 
meme, but the bottom text completely destroys these frame-induced expectations.

\section{Sources of humour in memes in Spanish}

Memes in Spanish do not differ radically from their counterparts in English. Among other reasons, users tend to resort to images from galleries that are valid pan-culturally, for example pictures of famous actors or sport players that all users know regardless of their background. Besides, the inferential strategies to generate humour, mainly based on the predicted steps in processing the text of the meme, its image or text-image combinations, are roughly the same across languages. We are equipped with a sophisticated evolved ability to turn coded inputs (utterances, pictures, nonverbal behaviours...) into meaningful and contextualised interpretations, and we do not engage in distinctive processing strategies in different languages such as English or Spanish. Therefore, users resort to similar humorous strategies across languages, mainly by playing with envisaged inferential strategies used to enrich the coded inputs into relevant interpretations (more on this below).

In this paper, two sources of humour in memes in Spanish will be addressed. Firstly, humour resulting from the processing of the text in the meme. And secondly, humour based on the relationship between the text and the image in the meme.

\subsection{Humour and meme text processing}

Memes are produced with an expected interpretation and (often humorous) effect. In order to be successful in the inferential process, the addressee has to contextualise the meme. This involves filling the gap between what is coded and what is intended in the meme and also accessing the intended set of contextual assumptions that allow for an optional interpretation. Indeed, meme authors expect other users to be able to identify cultural information attached to the memes, both regarding the image and the text, together with assumed background on the newsworthy events and individuals that might have triggered the design of the meme. Mutuality of contextual assumptions (including background knowledge) is essential for optimal meme comprehension.

For instance, an effective interpretation of meme (6) below demands that the user be acquainted with the fact that the national press was obsessed for a while with the question of whether soccer player Neymar would stay with the Barcelona soccer team (and Piqué's certainty that he would) as well as the enmity between Prime Minister Rajoy and Catalan separatist Puigdemont. A popular photograph had previously been published of Piqué and Neymar hugging each other. The top text of the meme is recognised by the reader as referring to the soccer context, but the accompanying photograph of the politicians contradicts this inference. Similarly, an appropriate understanding of meme (7) demands background knowledge about the problems that this model of mobile phone had concerning charging and setting itself on fire.

(6) Top text: Se queda!!!

[He will stay!!!].

Image: Picture of president of Spain, Mariano Rajoy, hugging Catalan separatist leader Puigdemont.

Bottom text: None. 
(7) Top text: Yo solo le dije al vecino...

[I only told my neighbour...].

Image: $\quad$ Picture of smiling girl in front of a burning house.

Bottom text: Ponga a cargar su Galaxy Note 7.

[Put your Galaxy Note 7 on charge].

During this gap-filling activity between what is coded and what is meant in the meme, users may engage in a number of inferential strategies. Specifically, according to relevance theory (Sperber and Wilson 1995), the process of comprehension starts with the identification (i.e., decoding) of the basic semantic representation of the text (called logical form), which is then enriched at the explicit level with inferential operations such as:

(a) Reference assignment, typical of indexicals (i.e. pronouns and adverbs) and proper names which are empty and have to be filled with a referent in a specific conversational context, as in (8).

(b) Disambiguation. Sometimes the hearer has to choose between two senses of the same word as possibly matching the one intended by the speaker, as in (9).

(c) Saturation. It takes place when the utterance demands from the hearer a kind of "inferential filling" of some elided part of the utterance without which the utterance makes little sense. Typical examples include the part in square brackets added in (10).

(d) Concept adjustment. On many occasions (if not all), the concept coded by a word is not relevant enough and has to be adjusted pragmatically, in such a way that the prototypical concept associated with that coded word is slightly different and merely resembles the one actually communicated in a context (called ad hoc concept). This communicated concept may be narrower than the coded concept (when the coded concept is too general), as in (11), or broader (when the coded concept is too specific), as in (12). In all of these cases, the ad hoc concept that is eventually communicated only "resembles" the concept literally coded in the utterance (see Carston 2002, among others).

(8) a. She was there with her and Thomas.

b. [Mary was at the party with Helen and Thomas Smith].

(9) I saw John by the bank [river bank/financial institution].

(10) Paracetamol is better [than what?] [for what?].

Louise is a better candidate [than whom?] [for what?].

(11) I am worried about Jim... He drinks too much.

[The coded concept drinks is too general and has to be narrowed. Specifically, Jim drinks too much alcohol].

(12) We entered the pub but we left since it was empty.

[The coded concept empty is too specific and has to be broadened as not literally empty; rather, with few people, including the staff].

All of these interpretive strategies may be exploited in the meme for the sake of generating humorous effects. Let us illustrate them with specific instances in Spanish, as shown in headings (1)-(4) below.

(1) Logical form. As was mentioned above, the initial stage of comprehension is to engage in a context-free decoding of the grammatical sequence of the utterance (called logical form), that is, to identify the words that the utterance is made of, without further making hypotheses about their intended interpretation. Normally, a unique grammatical string is 
identified upon decoding, but authors of memes may intentionally force the reader into humorously entertaining more than one logical form simultaneously. Take, for instance, the memes in (13-14):

(13) Top text: $\quad$ El hospital 12 de Octubre se queda sin anestesia.

[12 de Octubre hospital runs out of anesthesia].

Image: $\quad$ Picture of TV presenter Matías Prats.

Bottom text: Se acabó lo que sedaba.

[What sedates is over].

(14) Top text: La víctima murió ahorcada.

[The victim died by hanging].

Image: $\quad$ Picture of TV presenter Matías Prats.

Bottom text: Parece que todo concuerda.

[It seems that everything fits together].

These memes belong to the so-called "Matías Prats meme series" that will be analysed below, always involving punning associations between literal and idiomatic interpretations. In these memes, though, what interests us is the fact that for both bottom texts there are two possible logical forms if these are listened to, rather than read. In (13), we have simultaneous se acabó lo que sedaba (what sedates is over) and se acabó lo que se daba (an idiom in Spanish meaning roughly "that's all there is"). Crucially for humorous effects, both logical forms are possible and are entertained simultaneously, unlike the typical situation of comprehension, during which the addressee should only come up with a single logical form. In (14), the reader is also faced with two logical forms: todo concuerda (everything fits together) and todo con cuerda (everything with a rope), and both are again compatible with the situation depicted in the meme.

(2) Concept adjustment. As was mentioned above in passing, addressees normally adjust the concept coded by the words in the utterance. The outcome of this adjustment is an $a d$ hoc concept which is similar but not identical to the stabilised concept coded by the word in the utterance. They are ad hoc "because they are not linguistically given, but are constructed online in response to specific expectations of relevance raised in specific contexts. There is a difference then between ad hoc concepts, accessed by a spontaneous process of pragmatic inference, and lexicalized concepts, which are context-invariant" (Carston 2002, 322).

In certain contexts, as was mentioned above, the concept that the speaker intends to communicate is broader (i.e., less exact) than the concept that the word he/she has chosen literally communicates (or codes), as in (15). On other occasions, the concept that the speaker intends to communicate is narrower (i.e., more exact) than the concept that the word he/she has chosen literally communicates (or codes), as in (16):

(15) Don't worry. I'll be ready in two minutes.

[In a while, surely not literally two minutes].

This steak is raw.

[Not literally raw, but undercooked].

(16) Maria has a brain.

[Specifically, an outstanding brain, not simply a brain].

It will take some time to fix this car. 
[Specifically, longer than you imagine; longer than it would normally take].

Similarly, some memes in Spanish base their humorous quality on the user's conceptual adjustment of some word(s) in their texts, as in (17-18). In (17), the user has to entertain two ad hoc concepts for inútil (useless) which are similar but slightly different when applied to a person and to an inanimate object. In (18), two ad hoc concepts for separarse (break away) have to be inferred, one of an abstract quality, and one with a more physical denotation.

\begin{tabular}{|c|c|c|}
\hline (17) & Top text: & $\begin{array}{l}\text { Eres más inútil. } \\
\text { [You are more useless]. }\end{array}$ \\
\hline & Image: & The famous grumpy cat. \\
\hline & Bottom text: & $\begin{array}{l}\text { que la parte táctil de los mandos de la PS4. } \\
\text { [than the tactile part of the controls of the PS4] }\end{array}$ \\
\hline 8) & Top text: & $\begin{array}{l}\text { Si Cataluña se separa... } \\
\text { [If Catalonia breaks away]. }\end{array}$ \\
\hline & $\begin{array}{l}\text { Image: } \\
\text { Bottom text: }\end{array}$ & $\begin{array}{l}\text { Picture of football player Sergio Ramos. } \\
\text {...¿Aragón tendrá playa? } \\
\text { [Will Aragón have a beach?]. }\end{array}$ \\
\hline
\end{tabular}

Besides, a series of memes in Spanish is worth mentioning. These memes contain the same picture of actor Mike Myers (in his role as a spy in the film The spy who shagged $m e$ ). The processing of these memes demands concept broadening of the bottom text of the memes, which is invariably the same: A mi también me gusta vivir al limite (I also like to live on the edge) in order to fit the situations depicted in the memes which are, obviously, not as dramatic as the idiom normally communicates. Some of the top texts of these memes are provided in (19), together with their translations.

(19) ¿Así que vas a ver las campanadas en Canal Sur?

[So, you're going to watch New Year's chimes on the Canal Sur channel?]. ${ }^{4}$

Así que no silencias los grupos de WhatsApp.

[So you don't silence the WhatsApp groups].

Así que caminas por la calle en sandalias mientras llueve.

[So you walk in the street in sandals while it's raining].

Veo que llevas tu smartphone sin funda protectora.

[I see you're carrying your smartphone without a protective sleeve].

Así que te sientas en la tapa de un váter público sin mirar.

[So you sit on a public toilet without looking first].

(3) Disambiguation. Sometimes the hearer has to choose between two senses of the same word as possibly matching the one intended by the speaker. However, since

3. Aragón is the autonomous region of Spain, which is contiguous to Catalonia, in the west. Should Catalonia physically separate from Spain, Aragón would hypothetically be on the coast of Spain.

4. A tradition in Spain is to watch on TV the chimes of the clock in a central square in Madrid at 12 o'clock on the New Year's Eve. Families gather in front of the TV and eat one grape for every chime. However, some years ago one TV channel -Canal Sur- mistakenly inserted several ads while the chimes were in progress, thus upsetting the viewers, who lost count of the grapes that they were eating. 
comprehension is a cumulative inferential activity in which the interpretation of a previous chunk of discourse becomes the preliminary context upon which subsequent stretches are processed, very often hearers disambiguate meanings without even realising that there are alternative senses of the same word, just because the information that has already been processed biases the choice of one of these senses of the word. A classic example is the disambiguation of the word bat in (20), which is very easy due to the processing of the words that precede it (in italics):

(20) Your team is disqualified from the baseball game. Peter's bat is too grey.

We've chosen John's mouse for the experiment. Peter's bat is too grey.

This quality of ambiguous words in which one of the senses is much more likely than the other due to contextualisation (i.e., through make-sense frame construction) is exploited in some memes in Spanish for the sake of generating humorous effects. Two basic patterns may be isolated in this strategy:

1. Some portion of text contains an ambiguous word, but one of its meanings is highly likely and predictable due to the context in which it appears. Relevance theory predicts that, upon finding an interpretation that is optimally relevant (accessible for no gratuitous mental effort), the addressee will look no further and will not even consider other possible interpretations. However, the subsequent bottom text of the meme invalidates that initial likely and accessible sense of this word and the reader is forced to replace it with an initially less relevant and likely, but eventually correct interpretation. This new interpretation had not been considered, and the reader is therefore taken by surprise. This is illustrated by the meme in (21). As the reader comes across the word trio, he/she cannot help selecting "sexual threesome" as the intended interpretation. However, the bottom text forces a new, initially unlikely sense of the word: a musical trio. Of course, a parallel aim of the meme is to picture the girl as naive, to say the least.

(21) Top text: $\quad$ Mis amigas dicen que están haciendo un trío con mi novio.

[My girlfriends say that they are having a threesome/trio with my boyfriend].

Image: $\quad$ Picture of girl smiling.

Bottom text: Me encantaría escuchar las canciones que hacen.

[I'd love to listen to the songs that they sing].

2. Some portion of text contains an ambiguous word, but one of its meanings is highly likely and predictable due to the context in which it appears. Although the reader invariably selects one sense of the word as likely and intended, either the visual input of the meme makes another interpretation equally likely, or the previous text forces this dual likelihood. In both cases the reader is obliged to entertain both senses simultaneously, and this unusual interpretive pattern generates humorous effects. In Yus (2017) a similar analysis is performed regarding an advertisement whose text, "There is another way of saving money," is accompanied by a picture of a policeman trying to rescue a wad of bank notes from a ledge on a building. The most likely interpretation of saving money is "putting money aside in the bank", because of the lexical frequency of the joint appearance of these words. But in this advertisement, the picture depicted in the advertisement (the policeman trying to get the wad of bank notes) makes another interpretation of save 
money, namely "to rescue money," equally accessible. This simultaneity of interpretations leads to an inferential puzzlement in the audience, and hence to more attention being paid to the ad, as intended by its designers. A similar situation is found in some memes in Spanish. In (22), for instance, the word lava is ambiguous, meaning either "volcanic lava" or "he/she/it cleans." Due to the dual areas of contextualisation in the meme, the reader is unable to dismiss one sense in favour of the other one, thus entertaining both simultaneously:

(22) Top text: ¿Cuál es la montaña más limpia?

[Which is the cleanest mountain?].

Image: Regular guy (plays no role in humour).

Bottom text: El volcán, porque primero tira ceniza, pero después lava.

[The volcano, because it first throws away ash, but then lava].

(4) Explicit versus implicated. Interpretations of an utterance may be either explicit (explicature) or implicated (implicature) or both. Often the explicature matches the speaker's intended interpretation, but on other occasions the speaker intends some implicated interpretation as well and therefore the explicature becomes part of the "information plus context" that the hearer needs to reach that implicature. Everybody agrees that implicatures demand a lot of contextualisation, but one of the major contributions of relevance theory has been to show how obtaining explicit interpretations also demands from the addressee as much (or even more) contextualisation. Consider the dialogue in (23), adapted from Carston (2009):

(23) Tom: How was the party? Did it go well?

Ann: There wasn't enough drink and everyone left early.

(24) a. There wasn't enough alcoholic drink to satisfy the people at the party and so everyone who came to the party left it early, roughly before 2 o'clock.

b. The party did not go well at all.

c. Parties in which alcohol is scarce and people leave early are not good.

When Tom interprets Ann's utterance, he decodes her words and enriches them at the explicit level. And he needs contextual information for this inferential task: the coded concept drink is adjusted (narrowed) into specifically alcoholic drink; the scope of everyone is narrowed to everyone at the party, and early has to be interpreted as the time in their culture in which leaving a party at a certain time is considered early (for instance, 2 o'clock), which is different in other cultures. The resulting proposition would roughly be the explicature in (24a). Of course, as an answer to Tom's question, she also strongly implicates (24b) (an implicated conclusion or implicature). This is obtained by pairing the explicature in (24a) with encyclopaedic information about what it takes for parties not to be successful (the implicated premise in $24 \mathrm{c}$ ).

Additionally, one typical strategy to generate humour in memes is to force the reader to entertain both explicit and implicated interpretations simultaneously as presumably intended, even though they appear to be mutually exclusive. These interpretations are equally valid because contextual information makes both of them compatible, and this simultaneity puzzles the reader and leads to a humorous interpretive outcome. A Spanishspecific example is the "Matías Prats series," already mentioned and exemplified in this 
paper. The TV presenter is himself prone to using this kind of punning in his programmes, and therefore the reader of the meme is alerted to this quality of the meme as soon as the image of the TV presenter (invariably the same across memes) is identified. In a sense, this picture has a procedural role in the overall meme comprehension. The term procedural is contrasted with conceptual in relevance theory. In a nutshell, it can be stated that most words encode concepts, but some words give instructions as to how conceptual representations are to be inferred and hence encode procedural meaning. Blakemore and her followers applied this notion to connectives (Blakemore 1987) and discourse markers (Blakemore 2002), which constrain the inferential phase by indicating the kind of inferential process that the hearer should go through (hence reducing the eventual overall effort) in the subsequent stretch of discourse. This is what happens, for example, with but. Upon detecting this connective, the hearer is instructed that the next text is bound to be a contrast with what has been stated so far in the utterance.

In my opinion, the same can be said regarding the picture of Matías Prats. The reader of the meme identifies the picture and immediately infers that the accompanying text is bound to include some kind of punning element which will demand additional processing effort in exchange for a number of compensating humorous effects. Specifically, the punning relationship takes place between two interpretations of the text which are cleverly related, one explicit (a literal interpretation of the text) and one implicit (an interpretation of the text as an idiom). There is contrast but at the same time parallelism and compatibility between these interpretations and this parallel arrangement of interpretations amuses the reader. Some examples include (25-28) below:

(25) Top text: Un pirómano incendia un bloque de pisos.

[A pyromaniac sets a block of flats on fire].

Bottom text: Los vecinos están que echan humo.

[The neighbours are fuming].

(26) Top text: $\quad$ La Nasa sufre un recorte de presupuesto.

[Nasa suffers a budget cut].

Bottom text: Se ve que no están para tirar cohetes.

[They are probably cash-strapped].

(27) Top text: $\quad$ Superman es encontrado muerto en el puente de San Francisco.

[Superman is found dead on San Francisco bridge].

Bottom text: Se ve que estaba de capa caída.

[He was probably a bit down].

(28) Top text: American airlines denuncia a un piloto.

[American airlines sues a pilot].

Bottom text: Por estar en las nubes.

[For having his head in the clouds].

In (25), the idiom estar que echa humo means "to be utterly disgusted," but in the context of the meme, the literal interpretation is somehow also valid or at least tightly related (literally, "to expel smoke"). Notice that in English this explicit/implicit parallelism is also valid (to set on fire vs. to be fuming). In (26), the idiom no estar para echar cohetes means "to be short of budget," but the literal interpretation of the text, namely "to be unable to launch rockets" (due to loss of budget) is also valid. In (27), the idiom estar de capa caída means "to be down, to feel blue." Again, a purely literal interpretation of the 
phrase, "to have one's cape down" is utterly related to what has happened to the superhero (who actually wears a cape). Finally, in (28) we find a literal/idiomatic parallelism that also works in English. The idiom estar en las nubes means "to be distracted," which is incompatible with the pilot's task. However, the phrase literally means "to be in the clouds," which is more or less what the pilot does in his/her job.

\subsection{Humour and text-image combinations in memes}

Humour may also arise from the processing of text and image in the meme. Normally, memes whose humorous quality is only found in the text are less innovative and impact the reader less intensely than those whose intended interpretation demands the combination of the partial interpretations of the text and the image in the meme.

In Yus (2019), 100 memes were analysed and ascribed to a taxonomy of possible text-image combinations which was initially proposed for cartoon panels (McCloud 1994), due to the close resemblance between these memes and panels (Huntington 2015, 4). The text-image combinations are:

1. Word specific, where images illustrate but do not significantly add to a largely complete text in the meme. On some occasions, the image plays no role at all and all the humorous load of the meme is supported by the text only, as in (29), which plays with the news about the attempted independence of Catalonia and the word "dentist" with no communicative role played by the image:

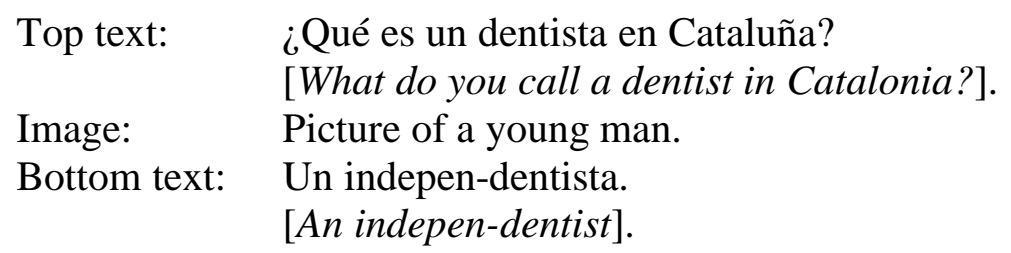

2. Image specific, where the image dominates, and words do not add significantly to the meaning of the image in the meme. The analysis revealed that this is a rare category in memes, since images generally either exhibit the role of exemplifying, emphasising or amplifying the meaning of the text, or are combined with the text in order to generate interpretations which can only be obtained from this combination.

3. Duo specific, where words and images send essentially the same message. Few memes exhibit this quality since the content, arranged across the two modes (image and text), would result in some degree of redundancy in meaning.

4. Additive, where words amplify or elaborate on an image or vice versa. Both sources of information cooperate in roughly the same direction. This is the image-text combination that is found in (30) below, where the woman's gesture of repulsion is corroborated by the information provided by the text of the meme, which also elaborates on the reason for the facial expression:

(30) Top text: Cuando sacas la basura.

[When you take the rubbish out].

Image: $\quad$ Picture of a woman showing repulsion.

Bottom text: Y la bolsa toca la pierna y está mojada.

[and the bag touches your leg and it's wet]. 
Besides, a frequent type of meme fitting this category is the abundant series of memes which share the same picture but contain different texts. The picture is usually a marked gesture by some famous character, normally an actor in a film. In this case, the main interest lies in the fact that the initial gesture (i.e., in the film) may be regarded as the default one, and then the different versions of text used are descriptions of other situations in which this gesture might also be produced. However, this also entails some kind of amplification or elaboration of the interpretation of the picture via adjustment. It could be said, then, that the initial gesture, as portrayed in the film, for example, may be labelled prototypical gesture, while the different variations provoked by the accompanying texts in the memes would generate adjusted gestures.

In Yus (2019), the term ad hoc visual referent adjustment is proposed for this "coded gesture plus variations in memes." The innovative inferential concept-related strategy found in memes is that there is also concept adjustment applied to the referent of the picture in the meme, specifically in those series of memes in which the picture is the same across memes and the users change the accompanying text, which users find funnier if they are aware of other versions of text for the same picture and of the coded gesture that was initially produced by that famous person (i.e., in a film).

Certainly, users are aware that there are many different texts for the same picture in a series of memes and know that sometimes the relationship between picture and text in the meme is not straightforward. Upon finding an instance of a series of memes, the user will pin down the extent and intensity of the gesture portrayed in the picture depending on the text that is above and under it, a proper case of adjustment but this time applied to the prototypical referent of the gesture depicted. The resulting ad hoc visual referent works specifically for this meme and not for other image-text relationships in other memes belonging to the same series.

Take, for instance, the memes reproduced in (31-33) below. The aforementioned prototypical gesture would be the one fitting the tragic event or news that triggered this gesture, whereas the reader is expected to adjust these gestures upon reading the texts above and below the picture, often by engaging in broadening, since the new situations are far less dramatic or tragic than the initial one leading to the prototypical gesture. This asymmetry between the initial coded gesture and the adjusted ones provokes a humorous interpretive outcome:

(31) Top text: $\quad$ Abrir por error la conversación de WhatsApp.

[Opening a WhatsApp conversation by mistake].

Bottom text: Que aparezca el doble check azul y estar obligado a contestar.

[Seeing blue double tick and being forced to reply].

(32) Top text: Me dijo que se iba a dormir.

[He told me he was going to bed].

Bottom text: $\quad$ Y aún sigue en línea.

[And he is still online].

(33) Top text: $\quad$ Le dije que había encontrado unas bragas rojas en el coche.

[I told him I'd found some red knickers in the car].

Bottom text: Me dijo que le había descubierto, que era Superman.

[He told me I had discovered him, that he was Superman]. 
Another example is found in examples (34-35) below, from the series of memes with a film still of actor Sean Bean in the TV series Game of Thrones, containing a well-known gesture (worried look) regarding the plot in the first season, which is meant to contrast with the suggested accompanying texts in the memes. These texts also entail an ad hoc visual referent adjustment, normally via broadening, because the new reasons for the worried look (as stated in the top and bottom texts) are much more trivial than the one that initially triggered the gesture in that TV series:

(34) Top text: $\quad$ Hay personas que hacen que te preguntes...

[There are people that make you wonder...].

Image: $\quad$ Picture of worried actor Sean Bean in Game of Thrones.

Bottom text: ¿De qué altura se caerían de la cuna?

[From what height did they fall from the cradle?].

(35) Top text: Me pregunto... ¿¿¿iPor qué tanto silencio???

[I wonder... why so much silence?].

Image: $\quad$ Picture of worried actor Sean Bean in Game of Thrones.

Bottom text: En este grupo qué estarán planeando.

[What might this group be up to?].

Furthermore, in Yus (2019, forthcoming) it was claimed that the image may aid in the strategy of a text-based incongruity. In (36), for example, there is an incongruity centred upon the user's disambiguation of the word beating, which encodes several possible senses. The user will inevitably select the sense that is most accessible and the scared look of the man facilitates this almost unconscious initial choice of one of these senses, which is again invalidated by the bottom text of the meme and replaced with a more unlikely (but eventually correct) interpretation.

(36) Top text: I love beating women

Image: $\quad$ Man with a very scary look on his face.

Bottom text: To the door so I can hold it open for them.

5. Parallel, where words and image follow different courses without intersecting. This category is absent in the memes analysed, since normally the eventual interpretation of memes relies on the combination of text and image, and it makes little sense to put both modes together in the meme if these are not somehow related.

6. Montage, where words are treated as integral parts of the image. This is a typical category in comics, since artists often skilfully connote the texts with iconic connotations (dripping words, creative use of bold letters, letters with a visually-connoted shape...). In a way, then, both modes become semiotically integrated. However, this category is absent in the corpus of memes, since text type (font, size...) is fixed and imposed upon the user by the available software.

7. Interdependent, where image or words together convey an idea that neither could convey alone. This category raises more interest for an analysis of how users obtain interpretations from the available information through interfaces. The fact that interpretations from memes in this category cannot be obtained from the partial meanings of text or image taken separately makes the meme utterly context-dependent and very attractive for the kind of analysis proposed in this paper. 
The most frequent mode of interaction in this category of memes is that in which the information from the image invalidates, to a greater or lesser extent, the information provided by the text. The most radical case is the one in which the image of the meme forces the opposite interpretation of the text to the one initially inferred, as in (37), in which the image of an extremely fat film character is incompatible with what is communicated by the text:

$\begin{array}{ll}\text { Top text: } & \text { Ya se me está notando. } \\ & {[\text { It is starting to show]. }} \\ \text { Image: } & \text { Picture of Jabba the Hutt (Star Wars character). } \\ \text { Bottom text: } & \text { Que voy al gym. }\end{array}$

[That I go to the gym].

\section{Concluding remarks}

In this paper an analysis has been carried out regarding possible ways in which memes in Spanish produce humorous effects. Two main areas have been addressed, one concerning how the text of the meme is processed for relevance (i.e., the reader filling the gap between what is coded textually in the meme and what is really intended by the maker of the meme with that text), and one concerning several possible combinations of the text and the image in the meme, sometimes with surprising effects.

In the former, several inferential strategies are exploited in Spanish memes for the sake of humour, including expectations of mutuality of information while processing the meme. Common cognitive strategies for text comprehension include reference assignment, disambiguation, concept adjustment and saturation. All of these may be used in the Spanish meme for the sake of generating humorous effects, including plays with explicit and implicated interpretations that are, by default, more or less likely in terms of relevance.

Concerning the latter, involving text-picture combinations, a taxonomy of these combinations taken from comics has been used (Yus 2019) and applied to Spanish memes: word-specific, image-specific, duo specific, additive, parallel and montage. In these combinations, the information provided by the image and the information provided by the text combine in creative, often clashing ways, which often provoke humorous effects.

Overall, in both cases the basic underlying framework, relevance theory, proves to be valid to account for the different ways in which humour in memes is intended and processed.

\section{Acknowledgements}

This research was supported by the Project FFI2015-64540-C2-1-P (Genhumid), a coordinate project funded by the Spanish Ministerio de Economía y Competitividad, and by the Project "Humor gender: Observatory of identity of women and men through humor" (PROMETEO/2016/052), funded by Generalitat Valenciana, Conselleria d'Educació, Investigació, Cultura i Sport. 


\section{References}

Ballesteros Doncel, Esmeralda. 2016. "Circulación de memes en WhatsApp: Ambivalencias del humor desde la perspectiva de género." Revista de Metodología de Ciencias Sociales 35: 21-45.

Blakemore, Diane. 1987. Semantic Constraints on Relevance. Oxford: Blackwell.

Blakemore, Diane. 2002. Relevance and Linguistic Meaning. The Semantics and Pragmatics of Discourse Markers. Cambridge: Cambridge University Press.

Breheny, Caitlin. 2017. “By Any Memes Necessary”: Exploring the Intersectional Politics of Feminist Memes on Instagram. MA Thesis. Uppsala University.

Carston, Robyn. 2002. Thoughts and Utterances. Oxford: Blackwell.

Carston, Robyn. 2009. "Explicit/implicit distinction." In The Pragmatics Encyclopedia, ed. by Louise Cummings. London: Routledge.

Carter, Jonathan. 2016. Enchanting Memes: Memetic Politics in the Face of Technocratic Control. PhD Thesis. University of Nebraska.

Coleman, E. Gabriella. 2012. "Phreaks, hackers, and trolls and the politics of transgression and spectacle." In The Social Media Reader, ed. by M. Mandiberg, 99-119. New York: New York University Press.

Csordás, Tamás, Dóra Horváth, Ariel Mitev, and Éva Markos-Kujbus. 2017. "Usergenerated Internet memes as advertising vehicles: Visual narratives as special consumer information sources and consumer tribe integrators." In Commercial Communication in the Digital Age. Information or Disinformation?, ed. by Gabriele Siegert, M. Bjørn Rimscha, and Stephanie Grubenmann, 247-265. Berlin: De Gruyter.

Denisova, Anastasia. 2016. Political Memes as Tools of Dissent and Alternative Digital Activism in the Russian-language Twitter. PhD Thesis. University of Westminster.

Dynel, Marta. 2016. "'I has seen image macros!' Advice animal memes as visual-verbal jokes." International Journal of Communication 10: 660-688.

Greidina, Nadejda L. 2017. "Memes in information warfare context in the South-East Ukraine." In Digital Transformation in Journalism and News Media Media Management, Media Convergence and Globalization, ed. by Mike Friedrichsen, and Yahya Kamalipour, 295-303. Berlin: Springer.

Hadley, Bree. 2016. "Cheats, charity cases and inspirations: disrupting the circulation of disability-based memes online." Disability \& Society 31(5): 676-692.

Huntington, Heidi E. 2015. "Pepper Spray Cop and the American Dream: Using synecdoche and metaphor to unlock Internet memes' visual political rhetoric." Communication Studies 67(1): 77-93.

McCloud, Scott. 1994. Understanding Comics: The Invisible Art. New York: Harper Collins.

Meikle, Graham. 2016. Social Media. Communication, Sharing and Visibility. Abingdon: Routledge.

Milner, Ryan M. 2012. The World Made Meme: Discourse and Identity in Participatory Media. PhD Thesis. University of Kansas.

Miltner, Kate M. 2014. “'There's no place for lulz on LOLCats': The role of genre, gender, and group identity in the interpretation and enjoyment of an Internet meme." First Monday 19(4).

Nissenbaum, Asaf, and Limor Shifman. 2017. "Internet memes as contested cultural 
capital: The case of 4chan's /b/ board." New Media \& Society 19(4): 483-501.

Segev, Elad, Asaf Nissenbaum, Nathan Stolero, and Limor Shifman. 2015. "Families and networks of Internet memes: The relationship between cohesiveness, uniqueness, and quiddity concreteness." Journal of Computer-Mediated Communication 20: 417433.

Shifman, Limor. 2014. Memes in Digital Culture. Cambridge, MA: The MIT Press.

Sperber, Dan, and Deirdre Wilson. 1995. Relevance. Communication and Cognition. 2nd edition. Oxford: Blackwell.

Suls, Jerry M. 1983. "Cognitive processes in humor appreciation." In Handbook of Humor Research, Vol. 1: Basic Issues, ed. by Paul E. McGhee, and Jeffrey H. Goldstein, 3957. New York: Springer-Verlag.

Tay, Geniesa. 2015. "Binders full of LOLitics: Political humour, internet memes, and play in the 2012 US Presidential Election (and beyond)." European Journal of Humour Research 2(4): 46-73.

Willmore, James, and Darryl Hocking. 2017. "Internet meme creativity as everyday conversation." Journal of Asia-Pacific Pop Culture 2(2): 140-166.

Yoon, InJeon. 2016. "Why is it not Just a joke? Analysis of Internet memes associated with racism and hidden ideology of colorblindness." Journal of Cultural Research in Art Education 33: 92-123.

Yus, Francisco. 1997. "La teoría de la relevancia y la estrategia humorística de la incongruencia-resolución." Pragmalingüística 3-4: 497-508.

Yus, Francisco. 2013a. "An inference-centered analysis of jokes: The Intersecting Circles Model of humorous communication." In Irony and Humor: From Pragmatics to Discourse, L. Ruiz Gurillo, and B. Alvarado (eds.), 59-82. Amsterdam and Philadelphia: John Benjamins.

Yus, Francisco. 2013b. "Analyzing jokes with the Intersecting Circles Model of humorous communication." Lodz Papers in Pragmatics 9(1): 3-24.

Yus, Francisco. 2016. Humour and Relevance. Amsterdam: John Benjamins.

Yus, Francisco. 2017. "Incongruity-resolution cases in jokes." Lingua 197: 103-122.

Yus, Francisco. 2018. "Identity-related issues in meme communication." Internet Pragmatics 1(1): 113-133.

Yus, Francisco. 2019. "Multimodality in memes. A cyberpragmatic approach." In Analyzing Digital Discourse: New Insights and Future Directions, ed. by Patricia Bou-Franch, and Pilar Garcés-Conejos Blitvich (eds.), 105-131. Cham (Switzerland): Palgrave Macmillan.

Yus, Francisco. forthcoming. "Incongruity-resolution humorous strategies in image macro memes." Internet Pragmatics.

\section{Address for Correspondence}

Francisco Yus

University of Alicante

Department of English Studies

Apartado 99

E-03080 Alicante

Spain

francisco.yus@ua.es 


\section{Biographical Notes}

Francisco Yus teaches pragmatics at the University of Alicante (Spain) and is also guest professor at the College of Foreign Languages, Fujian Normal University, China. He has specialised in the application of pragmatics (especially relevance theory) to media discourses and conversational issues. His main current research is focussed on a pragmatic approach to Internet-mediated communication (Ciberpragmática, Ariel, 2001; Ciberpragmática 2.0, Ariel, 2010; Cyberpragmatics, John Benjamins, 2011). Latest research also has to do with the application of relevance theory to the production and interpretation of humorous discourses (Humour and Relevance, John Benjamins, 2016). He is currently the Head of the Inter-university Institute of Applied Modern Languages of the Valencian Community (IULMA) at the University of Alicante, as well as Head of the Research Group "Professional and Academic English" at the same university. 